\title{
On the Contribution of Individual Components to Landing Gear Loads and Noise
}

\author{
Oksana Stalnov, Sarah Windiate†, David Angland; and Xin Zhang§ \\ University of Southampton, Southampton, Hampshire, SO17 1BJ, UK \\ Richard Ashworth \\ EADS Innovation Works UK, Bristol, BS99 7AR, UK
}

\begin{abstract}
The landing gear is a major contributor to the overall airframe noise during the approach to landing phase of flight. As such, considerable effort has been made to understand the complex flow physics of flow past the landing gear with the objective of reducing the noise. In the current study, the contribution of each landing gear component to the overall loads was conducted. Furthermore, the effect of three bogie inclination angles on flow and noise source maps was studied. The three configurations consisted of a horizontal $\left(\alpha=0^{\circ}\right)$, toe up $\left(\alpha=40^{\circ}\right)$ and toe down $\left(\alpha=-20^{\circ}\right)$ bogie inclination angles. Lastly, the effect of wrapped conformal fairing around the drag stay and torque arms was studied. Wind tunnel tests have shown a strong relationship between the inclination angle of the bogie and the noise source maps. The conformal fairings were successful in reducing the steady drag. At $5 \mathrm{kHz}$ noise emitted from the drag stay bracket at baseline configuration was attenuated with the drag stay - main strut fairing.
\end{abstract}

\section{Nomenclature}

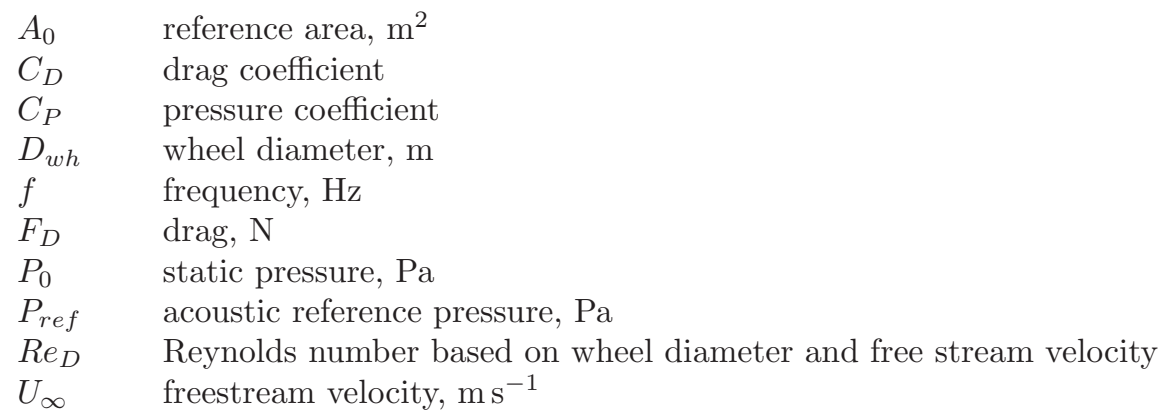

\section{Greek Symbols}

$\alpha \quad$ bogie inclination angle, deg.

$\theta \quad$ wheel azimuthal angle, deg.

$\nu \quad$ kinematic viscosity, $\mathrm{m}^{2} \mathrm{~s}^{-1}$

$\rho \quad$ density, $\mathrm{kg} \mathrm{m}^{-3}$

\section{Abbreviations}

SPL sound pressure level, dB (ref. 20 $\mu \mathrm{Pa}$ )

\footnotetext{
* Research Fellow, Faculty of Engineering and the Environment, Member AIAA.

$\dagger$ EngD Student, Faculty of Engineering and the Environment, Student Member AIAA.

Lecturer, Faculty of Engineering and the Environment, Member AIAA.

$\S$ Airbus Professor of Aircraft Engineering, Faculty of Engineering and the Environment, Associate Fellow AIAA.

『Research Engineer, TCC3 Aeromechanics.
} 


\section{Introduction}

TOR medium or large size civil transport aircraft, landing gear (or undercarriage) noise has been recognized $\mathrm{H}$ as a significant contributor to an aircraft's overall noise footprint during the approach to landing phase of flight. ${ }^{1,2}$ Landing gear noise has received a substantial amount of attention in the past fifteen years, due to its importance in defining the overall noise level for certification. The aerodynamic loads have received less attention, mainly because the landing gear is deployed for a short period of time in order to fulfil a specific mechanical task. As jet engines are becoming progressively quieter the attenuation of landing gear noise is of great engineering interest. This is especially true today, as noise regulations are becoming increasingly stringent with the European Union Flightpath 2050 targets that call for a $65 \%$ reduction of perceived aviation noise. To achieve this ambitious goal a better understanding of the flow around a landing gear is required.

Earlier efforts to study the complex flow around simplified landing gear components included isolated single wheel, ${ }^{3}$ nose two-wheel ${ }^{4,5}$ and main four ${ }^{6}$ - and six $^{7}$-wheel models. Most of the work on two-wheel configurations was conducted as part of the Landing Gear Noise database for Computational Aeroacoustic validation (LAGOON) programme. ${ }^{5}$ However studies involving single wheel or tandem wheel arrangement do not provide a complete picture of main landing gear flow interaction. While there are efforts to study main four-wheel landing gear, it should be noted that landing gear design is not globally uniform. Hence, simplified $1 / 4$ or $1 / 3$ scale models are different between various studies. These models usually are stripped of the associated complex features that contribute to noise generation at high frequencies.

Landing gears comprise of a serious of bluff body components in a wide range of diameters, thus resulting in complex flow and high noise levels in the far field. There are two main sources of landing gear noise. ${ }^{8}$ The first is the component self-noise, generated by an unsteady wake downstream of a bluff body. The second is the interaction noise, generated by the turbulent unsteady wake from the upstream components impinging on the downstream components. The self-noise generated by landing gears is broadband in nature. ${ }^{9}$ The typical noise generating mechanismof a landing gear at low frequencies is that of a compact dipole that is proportional to the unsteady force exerted on the fluid by the component. This mechanism is described by Curle's theory. ${ }^{10}$

One of the major components of overall landing gear noise is the bogie. ${ }^{11,12}$ Since the bogie creates significant flow blockage, a proper design of the bogie will affect the flow over the landing gear as a whole. Two main design parameters of the landing gear bogie are the number of wheels and the angle of the bogie beam. Small aircraft are likely to have two- or four-wheel landing gears, whereas larger aircraft will have four- or six-wheel landing gears. The choice of toe up or down for bogie angle for four- or six-wheel landing gears is governed by the overall architecture of the aircraft. Previous work into the effect of the bogie angle on the far field noise do not provide a clear relationship between the bogie inclination angle and far field noise. ${ }^{13,14}$

Initial noise reduction solutions included the application of solid or perforated fairings ${ }^{15,16}$ which prevented the impingement of high speed flow on the downstream landing gear components. These passive devices concentrated on the bogie area, where it is feasible to cover the non-aerodynamic components. However, the add-on devices have shown a limited potential for the noise reduction. ${ }^{17}$ Therefore, efforts are being made to investigate routes to reduce the landing gear noise by means of active flow control. One example is the use of plasma actuators to force an early separation on the upstream component, thus resulting in wider wake and weaker interaction noise. ${ }^{17,18}$ However, due to the limited control authority of plasma actuators, the full potential of active flow control has not yet been evaluated.

The aim of this work is to identify the contribution of the main landing gear components to the overall loads and noise. To achieve this goal we apply an incremental approach where the main landing gear components are incrementally applied to investigate their role in generation of loads and noise.

\section{Experimental Apparatus}

The aerodynamic and aeroacoustic measurements on a 1/4 scale simplified main landing gear model, previously used by Boorsma et al. ${ }^{15}$ were conducted in the wind tunnels of the University of Southampton. The major components constituting the model were interchangeable, thus allowing the application of an incremental approach. In the current model configuration only the main components of the landing gear were included, i.e. main strut, bogie with four wheels, and drag stay. The torque arms were set as part of 
the bogie assembly and thus were not interchangeable. The articulated link, that was previously attached to the main strut and bogie ${ }^{15}$ was omitted to allow rotation of the bogie in the range of inclination angles $\alpha$ between $40^{\circ}$ to $-20^{\circ}$, where positive $\alpha$ is defined toe-up. Details on the torque link and brake disks were accurately represented. Furthermore, the outside rim of the wheels were covered with hubs. The secondary components such as hydraulic folding and stowing mechanism, were omitted. The main strut had a diameter of $0.079 \mathrm{~m}$. The drag stay was approximated by simplified geometry of a circular cylinder of $0.056 \mathrm{~m}$ in diameter, was situated upstream at $25^{\circ}$ to the main strut. The small components, often referred as 'dressings', and considered to be an important source of high frequency noise, were also omitted. The wheel diameter and tread width are $0.36 \mathrm{~m}$ and $0.14 \mathrm{~m}$, respectively. For the purpose of analysing the results, the two sides of the wheel where denoted the 'hub side' with the hub cavity, and the 'axle side', where the axle is attached to the wheel.

The $x$-axis is in the direction of the flow, $y$-axis aligned with the landing gear main strut. The experiments were conducted at freestream velocities $\left(U_{\infty}\right)$ from 10 to $40 \mathrm{~ms}^{-1}$, corresponding to Reynolds number $R e_{D}=U_{\infty} D_{w h} / \nu$ from $1.4 \times 10^{5}$ to $9.2 \times 10^{5}$. Here the $D_{w h}=0.36 \mathrm{~m}$ is the diameter of the wheels and $\nu$ is the kinematic viscosity of air. The maximum wind tunnel speed of $40 \mathrm{~m} \mathrm{~s}^{-1}$ is approximately half the flight speed during the approach phase. Using Strouhal number $S t=f D_{w h} / U_{\infty}$ scaling, the relation of the measured frequencies to full scale flight conditions at $80 \mathrm{~m} \mathrm{~s}^{-1}$ results in approximately twice the values of the ones for the full scale flight.

The static pressures were measured at various positions on the landing gear's wheel surface. The centreline was instrumented with 19 pressure taps at increments of $5^{\circ}$ on a $90^{\circ}$ quadrant. Hence the wheel was rotated in four steps to obtain a $360^{\circ}$ centreline pressure distribution. Complimentary, to the centreline tapping, the shoulder of the tyre surface was instrumented with 32 additional taps. The rotation of the wheel in steps of $90^{\circ}$ increment yields four locations for measurement of the shoulder taps. A total number of 51 pressure taps were connected to a ZOC Scanivalve pressure scanner. Surface static mean pressure was measured on both upstream and downstream wheels. The mean surface pressure coefficient was evaluated using the standard definition $C_{P}=\frac{P-P_{0}}{1 / 2 \rho U_{\infty}^{2}}$. Here $P_{0}$ and $1 / 2 \rho U_{\infty}^{2}$ are the static and dynamic pressure measured with a pitot tube in the freestream.

In addition, a mixture of titanium dioxide, paraffin, and oleic acid was applied to the surface of the wheel. The wind tunnel was run at the desired speed until the solvent had evaporated and the oil is transported along the surface leaving an image of the time-averaged streaklines. Flow direction and separation lines are typical phenomena observed with oil flow visualisation technique. ${ }^{19}$ The streakline pattern at separation lines depends on the initial condition due to the build-up of the oil. Therefore, the mixture was applied in random patterns. The flow pattern was recorded with a standard digital camera.

The aerodynamic experiments were conducted in the University of Southampton RJ Mitchell wind tunnel. The tunnel is a closed circuit return type working section with maximum speed of $40 \mathrm{~m} \mathrm{~s}^{-1}$. The wind tunnel has an octagonal cross-section, $2.4 \mathrm{~m}$ in height and $3.5 \mathrm{~m}$ in width. The freestream turbulence intensity is less than $0.3 \%$ at $38 \mathrm{~m} \mathrm{~s}^{-1} .{ }^{20}$ A picture of the model in-situ is shown in Figure 1a. The model was mounted vertically to an overhead roof six-component balance to allow force measurements. The force data was acquired at a frequency of $1 \mathrm{kHz}$ over a period of 10 seconds. When the drag stay was in place it was attached to the balance via a beam to allow the forces to be acquired. This arrangement facilitates the rotation of the model to allow measurement of side forces. The model blockage, based on the model frontal area, was $3.2 \%$.

Since the fan in the RJ Mitchell wind tunnel is located near of the test section it is very challenging to estimate the location of the noise sources using a phased microphone array technique. Hence, the aeroacoustic experiments were conducted in the closed circuit $2.1 \mathrm{~m} \times 1.5 \mathrm{~m}$ wind tunnel. The freestream turbulence level is approximately $0.2 \%$ over the velocity range up to the maximum flow speed of $U_{\infty}=45 \mathrm{~ms}^{-1}$. To reduce wall effects the gear model was mounted horizontally, as shown in Figure 1b. The model blockage, based on the model frontal area, was $8.5 \%$.

\section{A. Phased Microphone Array}

To localize the noise sources a phased microphone array was placed on the floor of the University of Southampton's $2.1 \mathrm{~m} \times 1.7 \mathrm{~m}$ wind tunnel. The array consists of 112 flush-mounted Panasonic WM-60A omni-directional electrostatic microphones that were covered by a smooth Kevlar fabric to reduce the effect of boundary-layer noise. The nominal sensitivity and frequency response of the microphones are $-35 \mathrm{~dB}$ and $20 \mathrm{~Hz}$ to $20 \mathrm{kHz}$, respectively. The array was placed approximately $0.7 \mathrm{~m}$ from the centreline of the model. 


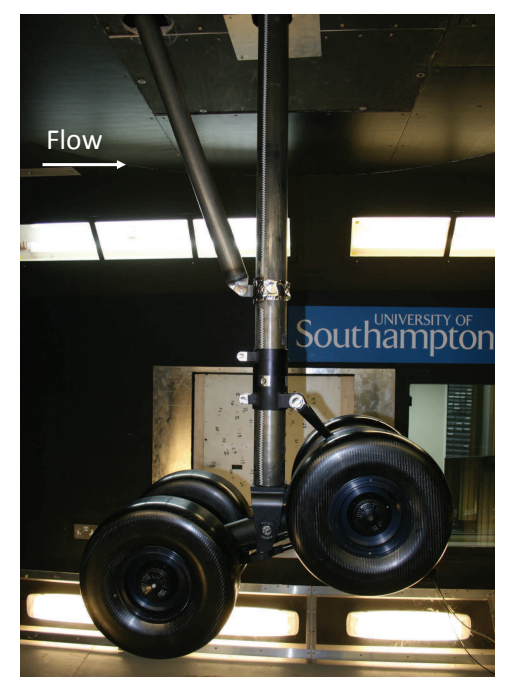

(a) Vertically mounted landing gear model in the $3.5 \mathrm{~m} \times 2.5 \mathrm{~m}$ wind tunnel. Bogie inclination angle is $\alpha=$ $-20^{\circ}$. The flow is from left to right.

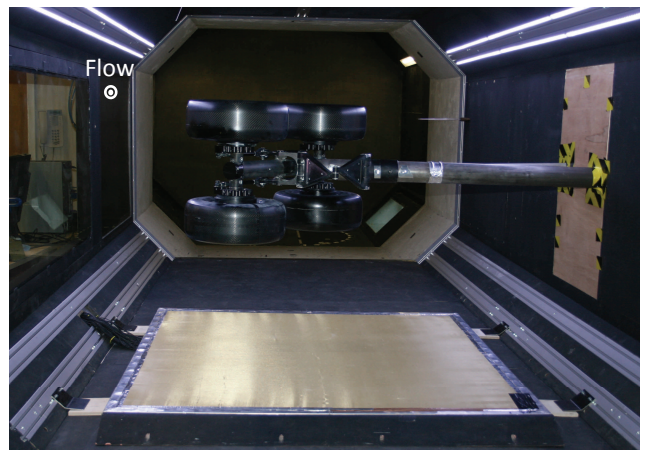

(b) Horizontally mounted landing gear model in the $2.1 \mathrm{~m} \times 1.7 \mathrm{~m}$ wind tunnel. The phased microphone array placed under the model. Bogie inclination angle is $\alpha=40^{\circ}$. View looking upstream.

Figure 1. The landing gear model in-situ in the wind tunnels of the University of Southampton, UK.

Each microphone was calibrated using a reference B\&K microphone, that was positioned adjacent to each array microphone in turn, and a point source of white noise on the floor of the test section. The transfer function from the reference microphone to the array microphone gave a frequency-dependent amplitude correction for each microphone.

A piezo buzzer was placed in the quiescent wind tunnel to localize the position of the model with the phased microphone array. The buzzer generates a coherent signal at a frequency at $3.2 \mathrm{kHz}$ at an amplitude of $90 \mathrm{~dB}$. It should be noted that a quantitative comparison of the wind tunnel data is challenging due to boundary layer noise, fan noise, and reflections from hard wind tunnel walls. The phased microphone data was acquired using a National Instruments Chassis equipped with 14 PXI-4472 cards allowing simultaneous data sampling at high frequency. In the current study the data was sampled at a frequency of $48 \mathrm{kHz}$ and analysed using a block size of 4096, yielding a frequency resolution of $12 \mathrm{~Hz}$. The sampling frequency was determined by previous frequency dependant amplitude calibration of the array. To reduce spectral leakage, a Hamming window function was applied to each block prior to performing the fast Fourier transform analysis. To achieve statistical convergence 100 blocks were averaged. The data was then post-processed using a conventional beamforming algorithm ${ }^{21}$ in the frequency domain. The diagonal elements (i.e. autospectra) of the cross-spectral matrix were omitted (zeroing out) to remove flow background noise and channel noise and accounting for this change in the number of terms of cross-correlation matrix. ${ }^{22}$ Source strength at each point of the scan grid is estimated by finding the value that gives the best match between measured cross-spectra and the field of a monopole located at that grid point.

\section{Experimental Results}

The results section is divided into two sections. Firstly the baseline aerodynamic and aeroacoustic results are presented and discussed. Then the passive flow control in form of a wrapped conformal fairing is shown and discussed.

\section{A. Aerodynamic Loads}

The forces acting on the landing gear model were measured in the RJ Mitchell wind tunnel. The landing gear drag coefficient is calculated using the formulae $C_{D}=F_{D} /\left(0.5 \rho U_{\infty} A_{0}\right)$, where $F_{D}$ is the load in the direction of the flow (or drag) and $A_{0}$ is a reference area. Since each landing gear component has a different 


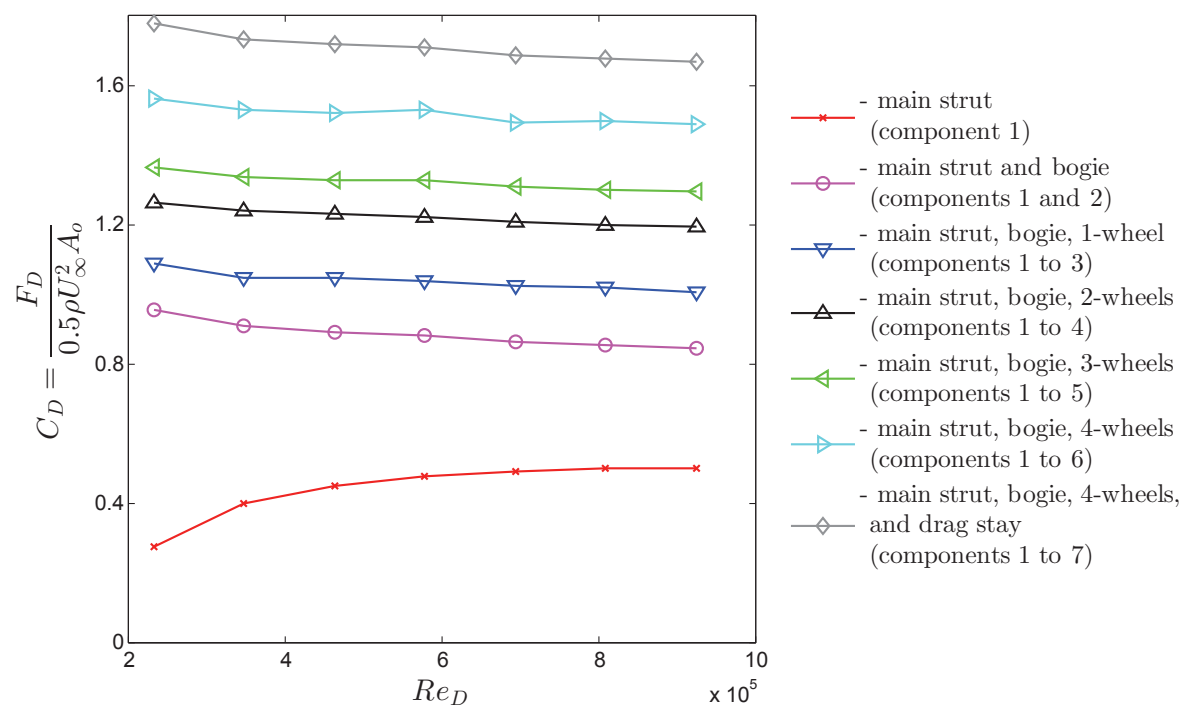

(a) Drag coefficient as a function of Reynolds number in incremental approach

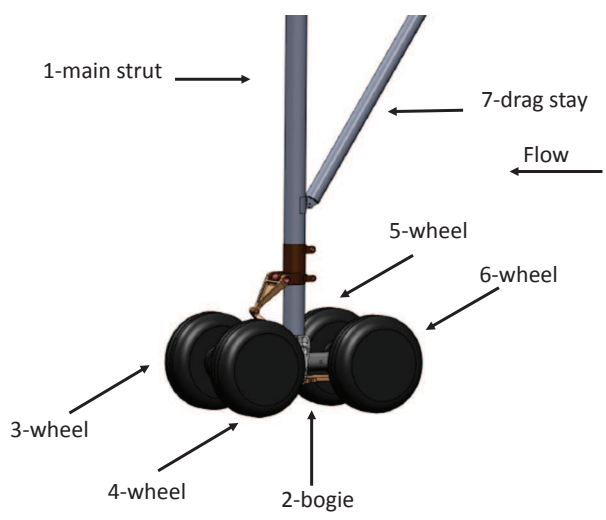

(b) Landing gear components

Figure 2. The effect of Reynolds number on drag coefficient in incremental approach. Bogie inclination angle is $\alpha=0^{\circ}$.

surface area at each inclination angle, a reference area of $A_{0}=\pi\left(D_{w h} / 2\right)^{2}$ was defined. This definition of drag coefficient is according to previous studies. ${ }^{13}$

The contribution of landing gear components to the drag at bogie angle $\alpha=0^{\circ}$ is depicted in Figure 2a. The interchangeable components are listed in Figure 2b. To achieve the supercritical flow, both the main strut and drag stay were tripped with $60^{\circ}$ 'zig-zag' turbulator tape of $6 \mathrm{~mm}$ point to point width and $0.5 \mathrm{~mm}$ thickness placed at $\pm 55^{\circ}$ from the stagnation. When the model consists of the main strut only (component 1) a strong Reynolds number effect is evident. Addition of the bogie (components 1 and 2) eliminates this strong Reynolds number dependence, as flow around the main strut with bogie is highly three-dimensional over the Reynolds numbers tested. Mounting the wheels one at a time, and later the drag stay, results in an increase in drag coefficient that acts as an approximate constant offset to the main strut with bogie configuration (components 1 and 2) over the Reynolds number range tested. It should be noted that the difference in drag due to addition of a component also account for the modified drag over the rest of the components.

\section{B. Flow Around the Bogie}

The effect of bogie inclination angle was studied for horizontal $\left(\alpha=0^{\circ}\right)$, toe up $\left(\alpha=40^{\circ}\right)$, and toe down $\left(\alpha=-20^{\circ}\right)$ bogie inclination angles. To visualize the complex flow features around the bogie surface 'oil-flow' 


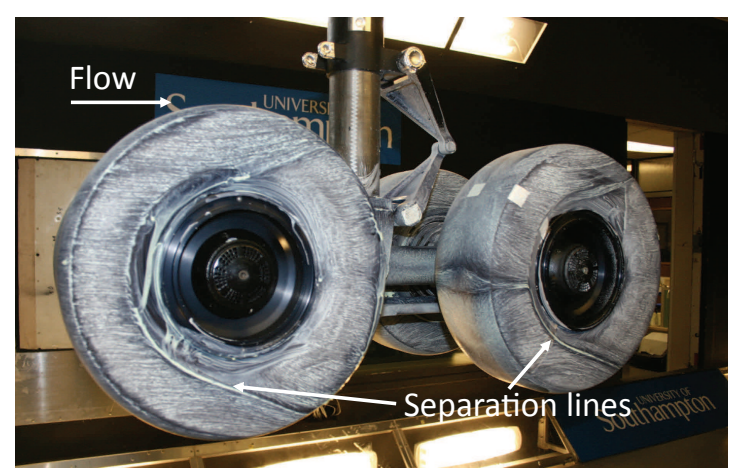

(a) $\alpha=0^{\circ}$

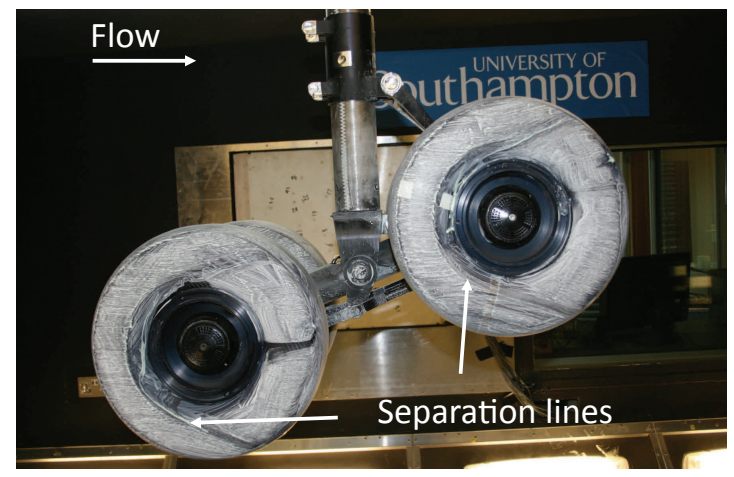

(c) $\alpha=-20^{\circ}$

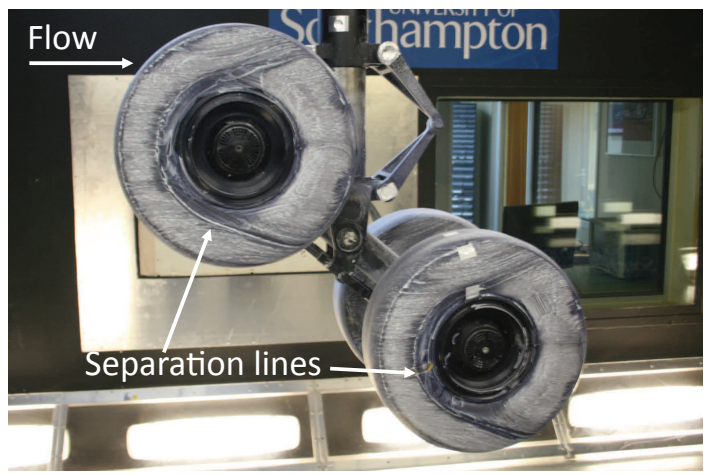

(b) $\alpha=40^{\circ}$

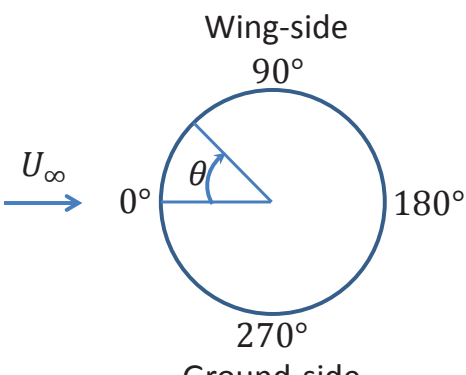

(d) Azimuthal angle definition.

Figure 3. Streaklines with 'oil-flow' visualization at three angles of bogie inclination at $\operatorname{Re}=9.2 \times 10^{5}$.

visualisation was applied on upstream and downstream wheels. The hubs of the wheels were not covered with the oil mixture. The surface streaklines for the three bogie angles, presented in Figure 3, show many similarities. The streaklines highlight oblique lines where the flow separates upstream of the hub cavities, leaving the area around the hub cavity clean from oil mixture. A region of low pressure persists on the ground and wing sides of the wheel towards the rear, which ultimately forms a vortex as it rolls-up over the aft of the wheel. The flow passing around the edges of the wheel meets towards the rear, where four vortices appear. From observations of oil accumulation on the aft region of the wheel, it is evident that four vortices with three-dimensional structures are generated. Similar structures were observed via oil-flow visualisation by Zdravkovich et al. ${ }^{23}$ behind short aspect ratio cylinders.

For the horizontal bogie $\left(\alpha=0^{\circ}\right)$ configuration there is a gap of $0.36 D_{w h}$ in size between the downstream and upstream wheels. The vortices in the wake of the upstream wheel are trapped in this gap and constantly impinge on the downstream wheel. Thus, creating a clear signature in surface oil flow visualisation of downstream wheel (see Figure 3a). Changing the bogie inclination angle allows these vortices do not directly impinge on the downstream wheel. At $\alpha=40^{\circ}$ the flow in the aft region of the upstream wheel directed downstream, as it is evident from the separation lines (see Figure 3b). Whilst at $\alpha=-20^{\circ}$ the flow at the aft region of the upstream wheel directed downstream, as it is evident from the separation lines (see Figure 3c).

To allow a quantitative study of the bogie angle effect, the mean unwrapped pressure distribution $C_{P}=$ $\frac{P-P_{0}}{1 / 2 \rho U_{\infty}^{2}}$ around the circumference of the downstream and upstream wheels is shown in Figure 4 . The drag stay was removed to allow a quantitative comparison between previous studies (configuration 1 to 6 , see Figure 2b). The azimuthal local angle $\theta$ is measured from the upstream face of the wheel clockwise and increase in a clockwise direction (see Figure $3 \mathrm{~d}$ ), where $\theta=0^{\circ}$ corresponds to the stagnation point. Once the bogie angle was changed the azimuthal angle was geometrically corrected to set the $x$-axis in the direction of the freestream flow. It is immediately evident that the mean pressure distribution is almost independent of Reynolds number over the Reynolds numbers tested in this study. A flow around a finite length bluff 
body with free-ends is three-dimensional. Thus, gives rise to the base pressure coefficient and the minimum pressure coefficient of $C_{P} \approx-1$ around $\theta=90^{\circ}$. The separated shear layers from the edges of the wheel form four counter-rotating swirling vortices.

For the horizontal bogie configuration $\left(\alpha=0^{\circ}\right)$, it is immediately noticeable that for the upstream wheel the stagnation pressure of $C_{P}=1$ is locating the stagnation point at $\theta=0^{\circ}$. The centerline pressure shows a continuous decrease in pressure coefficient, corresponding to flow acceleration, from $\theta=0^{\circ}$ to about $\theta= \pm 90^{\circ}$. The base pressure show slight dependence on the Reynolds number with two dips in rear region. A similar dip is shown in the front region of the downstream wheel, thus indicating unsteady flow in the gap between the upstream and downstream wheels. The minimum pressure coefficient $C_{P_{\min }}$ is around $80^{\circ}$, similar to a two-dimensional cylinder.

Increasing the bogie inclination angle to $\alpha=40^{\circ}$ (toe up configuration) results in asymmetric flow around the upstream wheel. The inclination of the bogie with respect to the frestream displaces the flow around the wheels and prevents the unsteady flow in the wake of the upstream wheel from impinging on the downstream wheel. The downstream wheel encounters freestream flow in the stagnation region, $C_{P}=1$, resulting in an almost symmetric pressure distribution around the downstream wheel. Whilst, reducing the bogie angle to $\alpha=-20^{\circ}$ (toe down configuration) results in stronger asymmetric flow around the downstream wheel and almost symmetric pressure distribution around the upstream wheel. 


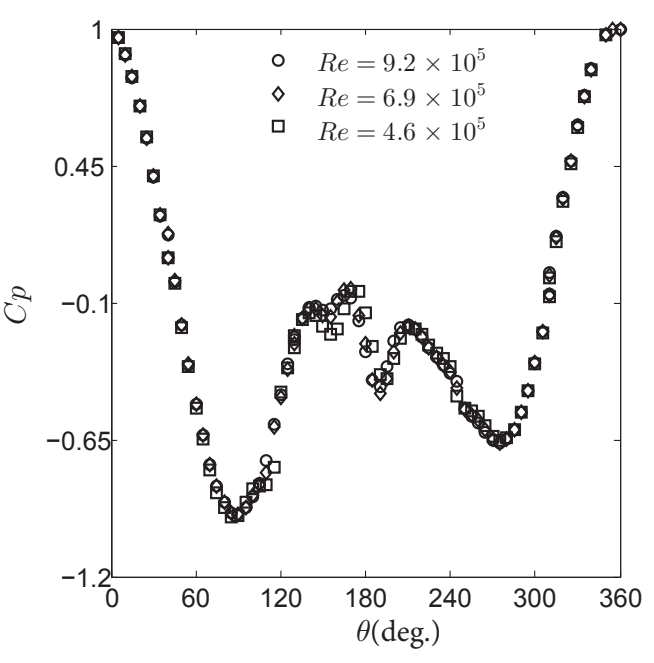

(a) Upstream wheel at $\alpha=40^{\circ}$

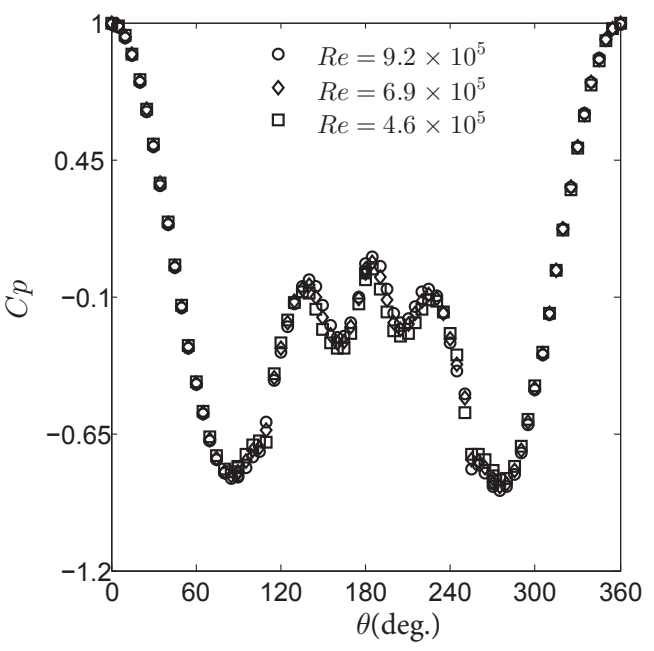

(c) Upstream wheel at $\alpha=0^{\circ}$.

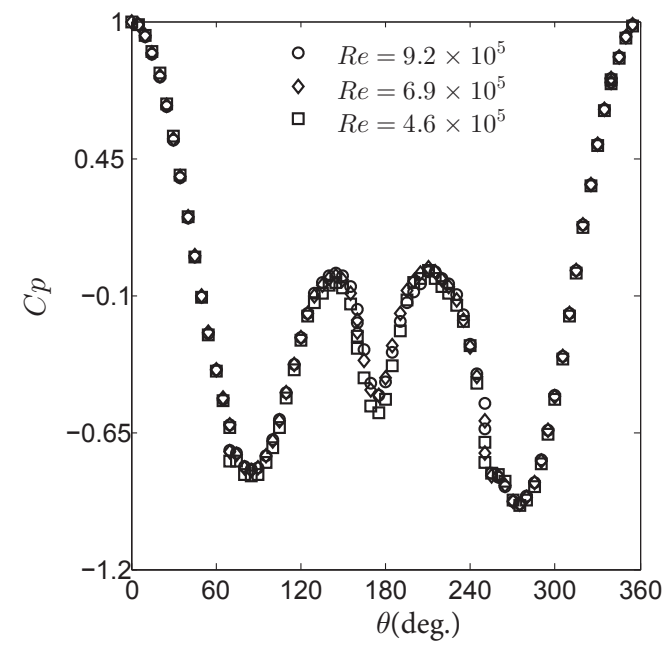

(e) Upstream wheel at $\alpha=-20^{\circ}$

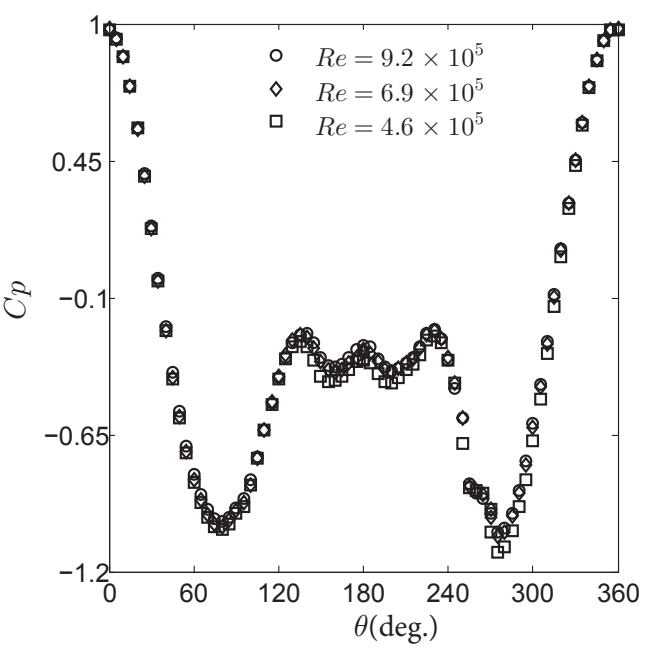

(b) Downstream wheel at $\alpha=40^{\circ}$

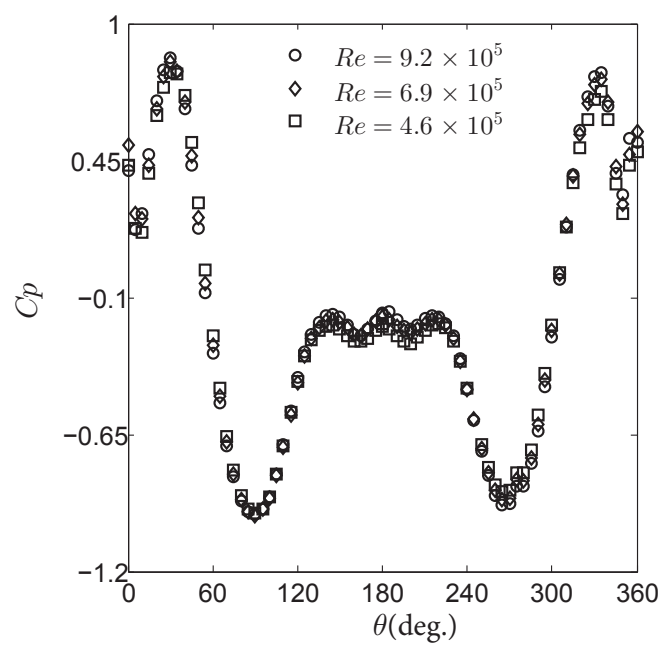

(d) Downstream wheel at $\alpha=0^{\circ}$

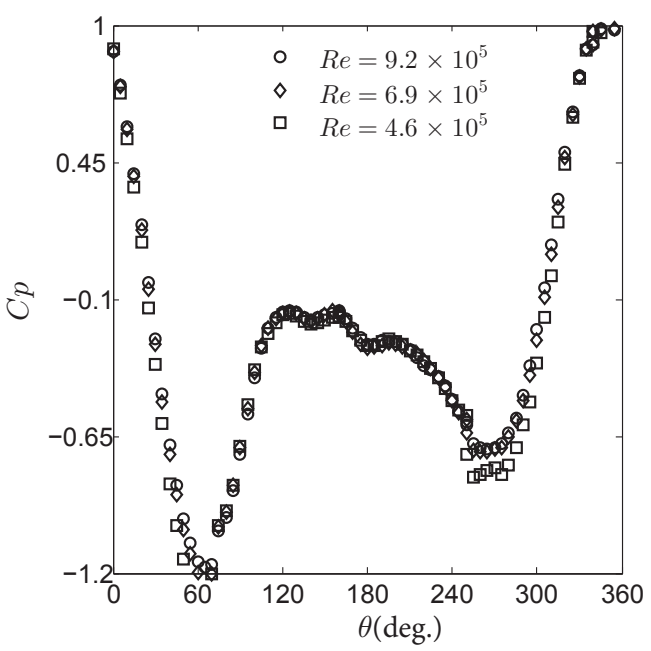

(f) Downstream wheel at $\alpha=-20^{\circ}$

Figure 4. Distribution of mean azimuthal pressure on the upstream and downstream wheels at three bogie inclination angles. The positive azimuthal angle is defined clockwise. 
To study the wind tunnel effects on mean pressure distribution, the centreline static pressure on the upstream wheel was acquired in both experimental facilities, and compared to Lazos. ${ }^{24}$ The centreline static pressure on the downstream wheel was acquired only in the $2.4 \mathrm{~m} \times 3.5 \mathrm{~m}$ wind tunnel. The immediate effect is that static pressure drops to a lower value on both the ground and wing side of the wheel around $\pm 90^{\circ}$ at the facility with higher model blockage, where the minimum pressure coefficient on the ground side of the wheel is slightly lower than the ground side in both facilities. The suction location is in agrement with Lazos. Study by Lazos is shown for a broad comparison of the centerline pressure, where the main difference is in the base pressure region. The bogie blockage in Lazos facility is around $16 \%$, thus demonstrating that the difference between the two experiments conducted at the University of Southampton is indeed due to blockage effects. The base pressure is affected by the size of the gap between the upstream and downstream wheels. In the Lazos landing gear model the size of the gap between the tandem wheels is $0.15 D$, while for the current model the size of the gap is $0.36 \mathrm{D}$. Therfore, slightly different base pressure behaviour is observed.

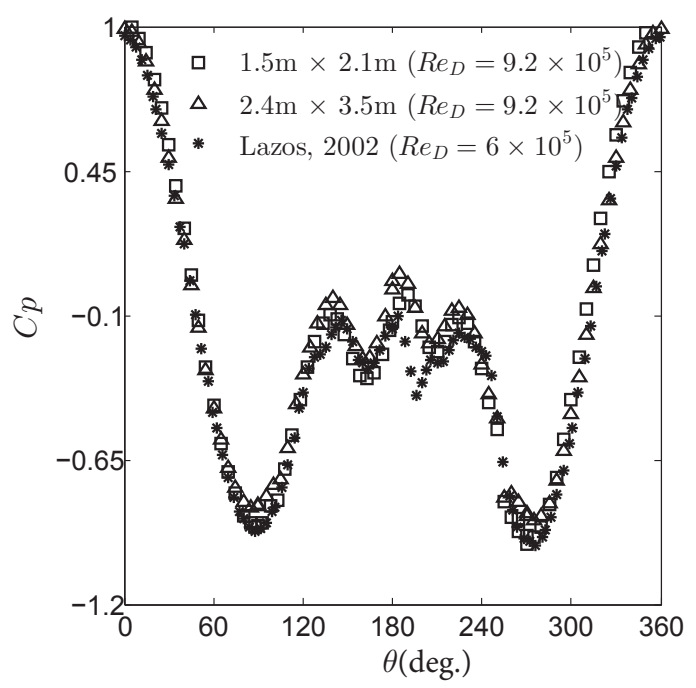

Figure 5. The effect of wind tunnel blockage on mean azimuthal pressure on the upstream wheel at bogie inclination of $\alpha=0^{\circ}$.

\section{Aeroacoustic Measurements}

To study the effect of bogie inclination angle on the noise emitted from the landing gear a phased microphone array was mounted on the ground in the $2.1 \mathrm{~m} \times 1.5 \mathrm{~m}$ wind tunnel, thus corresponding to 'side-view' configuration. Figure 6 compares noise source maps at three narrow-band frequencies and three inclination angles at $R e_{D}=9.2 \times 10^{5}$. The beamforming scan plan was defined at the centre of the model that pass through the centre of main strut, corresponding to vertical distance of $0.71 \mathrm{~m}$ from the phased microphone array. The noise in the $2 \mathrm{kHz}$ narrow-band radiated from the wheel hub area. At all three inclination angles of the bogie the downstream wheel is a stronger noise source, as it encounter unsteady flow from the upstream wheel. The torque arms become a significant noise source at $\alpha=40^{\circ}$, where the unsteady flow from the upstream wheel impinges on the main strut and torque arms. The noise at $3.5 \mathrm{kHz}$ narrow-band radiates from the torque arms area. The noise at $5 \mathrm{kHz}$ narrow-band radiates from the junctions between the drag stay -main strut and torque arm brackets. 


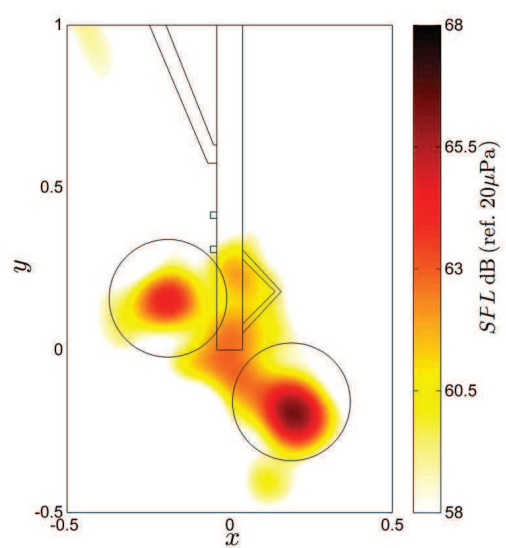

(a) $f=2 \mathrm{kHz}, \alpha=40^{\circ}$

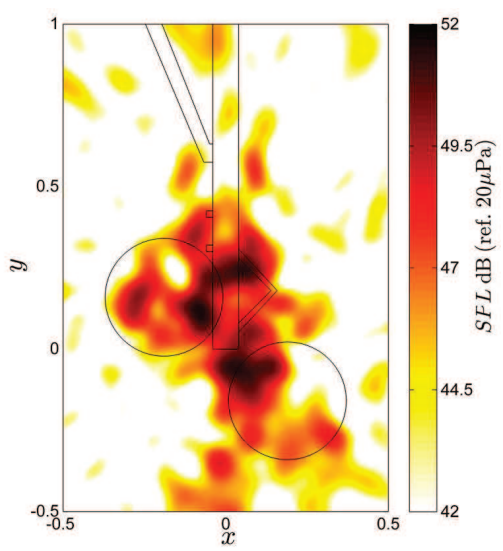

(d) $f=3.5 \mathrm{kHz}, \alpha=40^{\circ}$

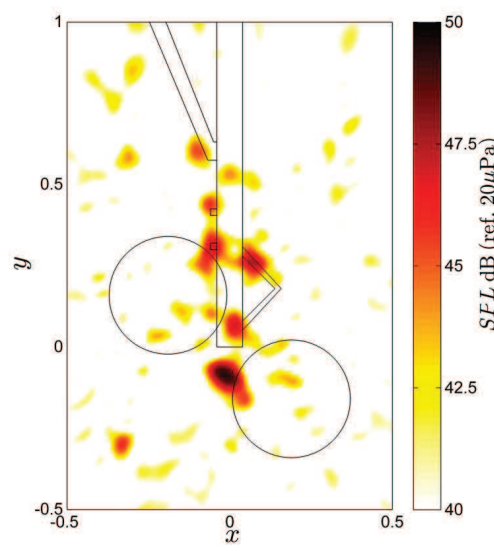

(g) $f=5 \mathrm{kHz}, \alpha=40^{\circ}$

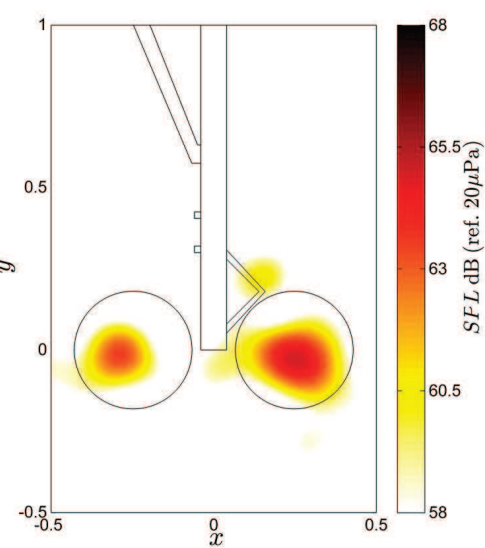

(b) $f=2 \mathrm{kHz}, \alpha=0^{\circ}$

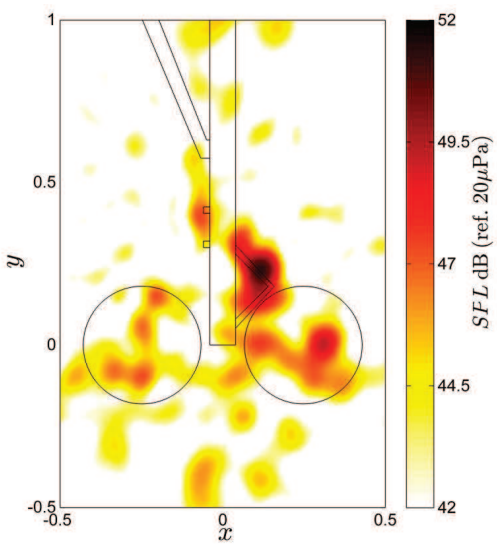

(e) $f=3.5 \mathrm{kHz}, \alpha=0^{\circ}$

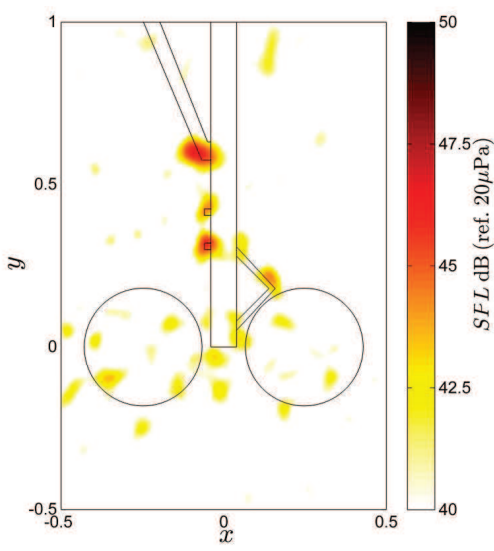

(h) $f=5 \mathrm{kHz}, \alpha=0^{\circ}$

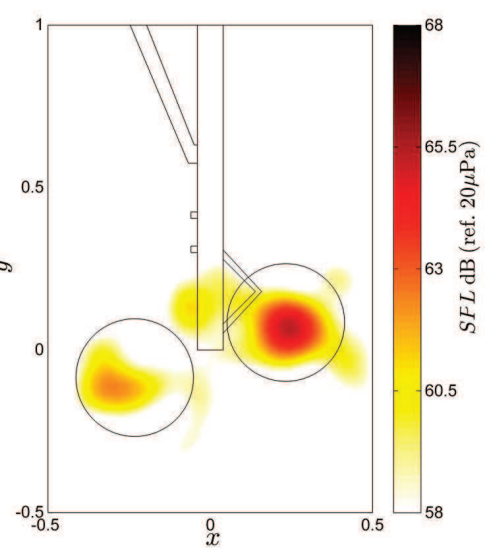

(c) $f=2 \mathrm{kHz}, \alpha=-20^{\circ}$

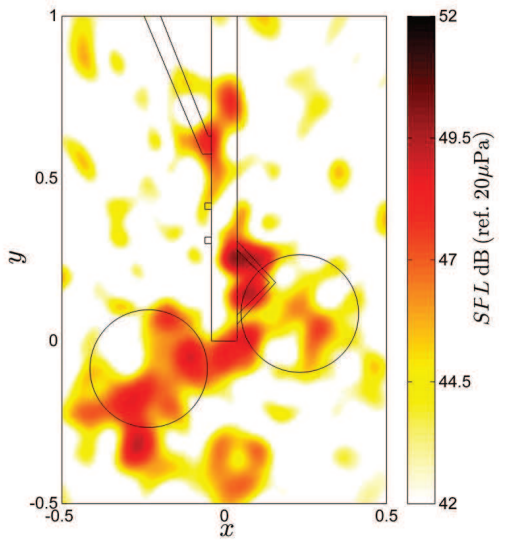

(f) $f=3.5 \mathrm{kHz}, \alpha=-20^{\circ}$

Figure 6. 'Side-view' beamforming maps for three bogie inclination angles and three narrow-band frequencies at $\operatorname{Re}_{D}=9.2 \times 10^{5}$. The beamforming scan plan was defined at the centre of the model that pass through the centre of main strut, corresponding to vertical distance of $0.71 \mathrm{~m}$ from the phased microphone array. 


\section{Passive Flow Control}

This section described passive flow control in the form of a wrapped conformal fairing to reduce the loads and associated noise. Two configurations were considered. The first configuration is a conformal fairing around the drag stay and main strut (see Figure 7a). The second configuration is of two conformal fairings, with an additional conformal fairing placed around the torque arms and main strut (see Figure 7c). The objective of the fairing is to prevent the unsteady separated flow from impinging on the downstream components.

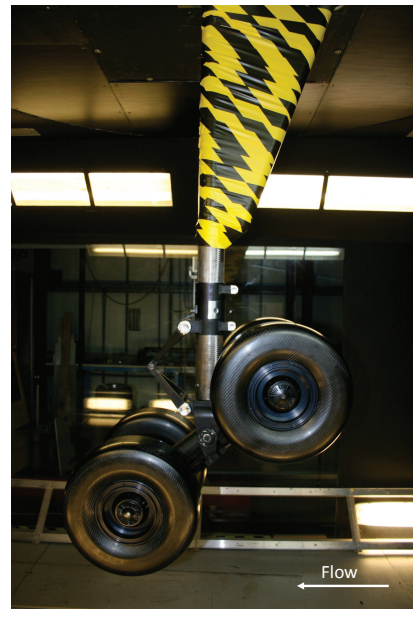

(a) Drag stay fairing at bogie inclination angle of $\alpha=40^{\circ}$.

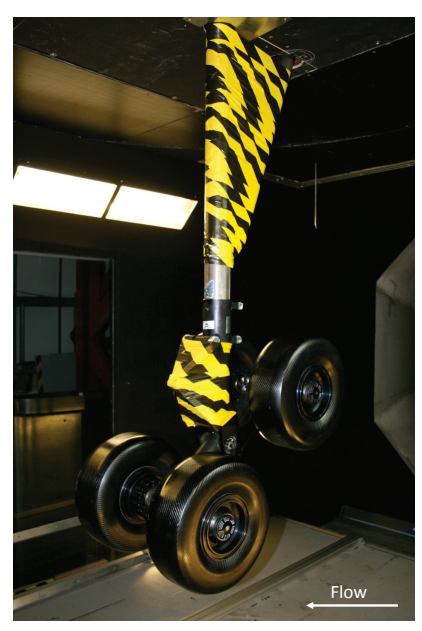

(c) Drag stay and torque arms fairing at bogie inclination angle of $\alpha=40^{\circ}$.

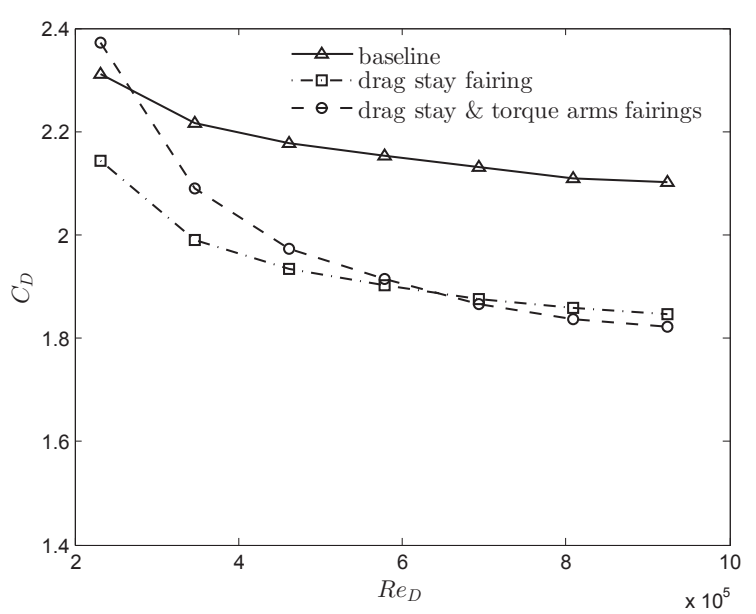

(b) $\alpha=40^{\circ}$

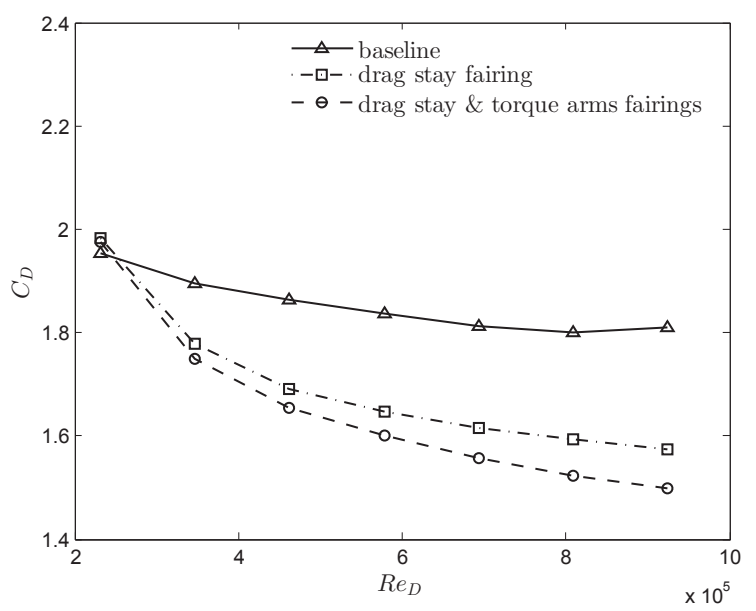

(d) $\alpha=-20^{\circ}$

Figure 7. The effect of passive flow control on drag at two bogie inclination angles. Passive flow control is in the form of wrapped conformal fairing around the drag stay - main strut.

At toe up $\left(\alpha=40^{\circ}\right)$ configuration, the flow encounters significant blockage, resulting in high drag coefficient $C_{D} \approx 2.1$ in baseline (no fairing) configuration. Application of drag stay - main strut fairing results in significant drag reduction of $12 \%$ at Reynolds number of $9.2 \times 10^{5}$ (corresponding to free stream velocity of $\left.U_{\infty}=40 \mathrm{~m} \mathrm{~s}^{-1}\right)$. The drag stay fairing is much more effective in reducing the mean drag.

At toe down $\left(\alpha=-20^{\circ}\right)$ configuration, the baseline mean drag is $C_{D} \approx 1.8$. Application of drag stay main strut fairing result in reduction of $13 \%$ in drag at Reynolds number of $9.2 \times 10^{5}$. Application of torque arm - main strut fairing on the drag stay results in additional drag reduction for $R e>3.4 \times 10^{5}$. In this 
configuration the flow directed toward the drag stay, thus resulting in impingement of unsteady flow on the drag stay and torque arms.

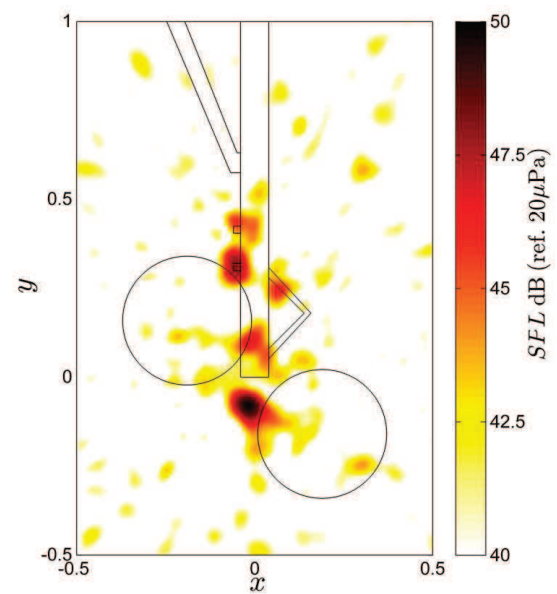

(a) Drag stay - main strut fairing at $\alpha=40^{\circ}$

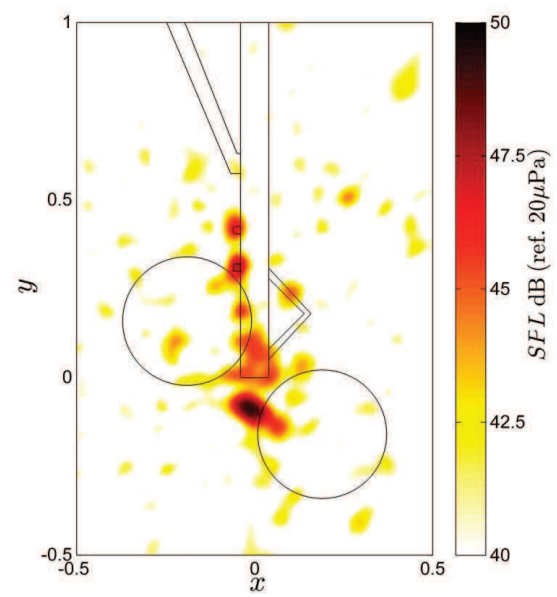

(c) Drag stay - main strut and torque arms - main strut fairings at $\alpha=40^{\circ}$

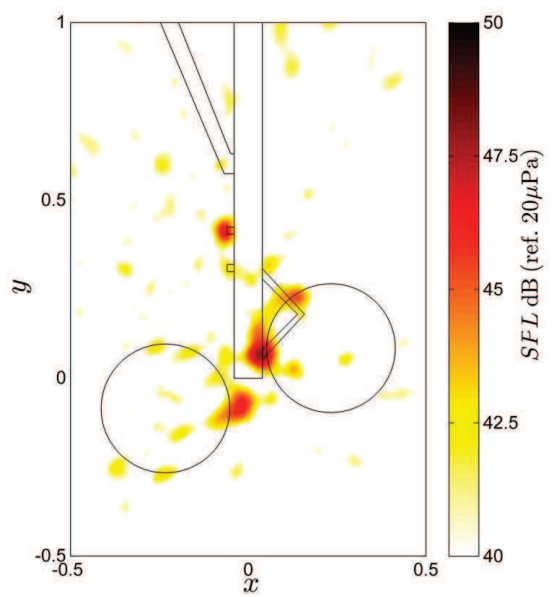

(b) Drag stay - main strut fairing at $\alpha=$ $-20^{\circ}$

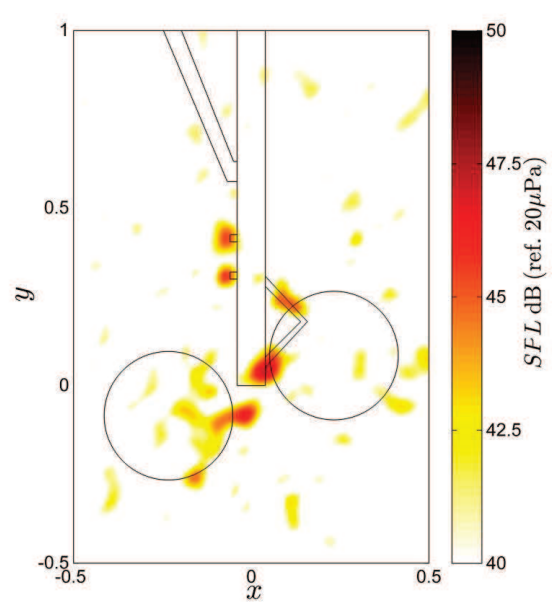

(d) Drag stay - main strut and torque arms - main strut fairings $\alpha=-20^{\circ}$

Figure 8. The effect of passive flow control on 'side-view' beamforming maps at two bogie inclination angles, at $5 \mathrm{kHz}$ narrow-band frequency, at $R e_{D}=9.2 \times 10^{5}$. The beamforming scan plan was defined at the centre of the model that pass through the centre of the main strut, corresponding to vertical distance of $0.71 \mathrm{~m}$ from the phased microphone array.

Phased microphone array maps with addition of conformal fairings at $\alpha=40^{\circ},-20^{\circ}$ at $5 \mathrm{kHz}$ are shown in Figure 8. This narrow-band frequency is shown because in baseline (without fairing) configuration the noise radiates from the junction between the drag stay -main strut and torque arm brackets. Addition of drag stay - main strut fairing results in attenuation of the noise emitted from the drag stay bracket. No deferable difference is shown for addition of the torque arms - main strut bracket.

\section{Conclusions}

This detailed series of aerodynamic and aeroacoustic experiments have shed some light into the complex flow physics around rudimentary landing gear geometry. The landing gear model consisted of a main strut, torque link, bogie with four wheels, and a simplified drag stay of circular cross-section. To study the effect of bogie inclination angle, three bogie angles were set. Surface flow visualization has been conducted on the bogie wheels, showing clearly the foot prints of the vortex structures. The relative position of the upstream 
and downstream wheels determines the location of the flow separation line on the upstream wheels. In the horizontal configuration the vortices from the upstream wheels are trapped in the gap between the wheels. In the toe down configuration the vortices from the upstream wheel are shed downstream with lower impingement levels on the downstream wheels. In the toe up configuration the vortices are shed downstream while impinging on the downstream components. The 'side-view' beamforming maps reveal that the wheels are significant noise source at $2 \mathrm{kHz}$. The torque arms become a significant noise source at toe up $\left(\alpha=0^{\circ}\right)$ configuration, due to impingement of unsteady flow from the upstream wheel.

Two fairing configurations were tested. Covering the gap area between the drag stay and main strut results in reduction of the mean drag. As the drag stay bracket is a significant noise source in baseline configuration, shielding it results in noise reduction. An application of a second fairing results in less pronounced drag reduction, compared to one fairing configuration. At $3.5 \mathrm{kHz}$ the noise is emitted from the drag stay bracket, with addition of drag stay fairings the levels emitted from the drag stay bracket are reduced. These results clearly show that especially for high frequencies, shielding sharp objects from high speed impingement yields noise reduction.

\section{Acknowledgement}

This work was supported by the EADS Innovation Works United Kingdom. We would also like to acknowledge David Marshall for his help during the experiment.

\section{References}

${ }^{1}$ Souliez, F. J., Long, L., Morris, P., and Sharma, A., "Landing gear aerodynamic noise prediction using unstructured grid," International Journal of Aeroacoustics, Vol. 1, No. 2, 2002, pp. 115-135.

${ }^{2}$ Dobrzynski, W., Chow, L., Guion, P., and Shiells, D., "A European study on landing gear airframe noise sources," AIAA/CEAS Paper 2000-1971, 2000.

${ }^{3}$ Zhang, X., Ma, Z., Sanderson, M., and Bissessur, P., "Aerodynamic and acoustic measuremnts of a single landing gear wheel," AIAA Paper 2013-2160, 2013.

${ }^{4}$ Guo, Y., Yamamoto, K., and Stoker, R., "Experimental study on aircraft landing gear noise," Journal of Aircraft, Vol. 43, No. 2, 2006, pp. 306-317.

${ }^{5}$ Sanders, L., Manoha, E., Khelil, S. B., and Francois, C., "LAGOON : CFD/CAA coupling for landing gear noise and comparison with experimental database," AIAA paper 2011-2822, 2011.

${ }^{6} \mathrm{Li}$, Y., , Smith, M., and Zhang, X., "Measurement and control of aircraft landing gear broadband noise," Aerospace Science and Technology, Vol. 23, 2011, pp. 213-223.

${ }^{7}$ Humphreys, W. and Brooks, T., "Noise Spectra and Directivity For a Scale-Model Landing Gear," AIAA paper 2007$3458,2007$. 3539.

${ }^{8}$ Dobrzynski, W. M., "Airframe noise-landing gear noise," Encyclopedia of Aerospace Engineering, Vol. 6, 2008, pp. 3529-

${ }^{9}$ Joseph, P. and Smith, M., Aircraft Noise, London, Spon Press, London, 2004, pp. 292-346.

${ }^{10}$ Curle, N., "The influence of solid boundaries upon aerodynamic sound," Proceedings of the Royal Society of London. Series A. Mathematical and Physical Sciences, Vol. 231, No. 1187, 1955, pp. 505-514.

11 "Research into landing gear airframe noise reduction," Tech. rep.

${ }^{12}$ Ravetta, P., Burdisso, R. A., and Ng, W., "Wind tunnel aeroacoustic measurements of a $26 \%$-scale 777 main landing gear model," AIAA/CEAS paper 2002-2885, 2004.

${ }^{13}$ Mierlo, K., Takeda, K., and Peers, E., "Computational analysis of the effect of bodie inclination angle on landing gear," AIAA Paper 2010-3971, 2010.

${ }^{14}$ Smith, M., Chow, L., and N.Molin, "The influence of aerodynamic interactions between components on landing gear noise," AIAA Paper 2013-2118, 2013.

${ }^{15}$ Boorsma, K., Zhang, X., and Molin, N., "Landing gear noise control using perforated fairings," Acta Mechanica Sinica, Vol. 26, No. 2, 2010, pp. 159-174.

${ }^{16}$ Dobrynski, W., Chow, L. C., Guion, P., and Shields, D., "A European study on landing gear airframe noise sources," AIAA Paper 2000-1971, 2000.

${ }^{17} \mathrm{Li}$, Y., Zhang, X., and Huang, X., "The use of plasma actuators for bluff body broadband noise control," Experiments in fluids, Vol. 49, No. 2, 2010, pp. 367-377.

${ }^{18}$ Huang, X., Zhang, X., and Li, Y., "Broadband flow-induced sound control using plasma actuators," Journal of Sound and Vibration, Vol. 329, No. 13, 2010, pp. 2477-2489.

${ }^{19}$ Smits, A. and Lim, T., Flow visualization: techniques and examples, Vol. 1, Imperial College Press London, UK, 2000.

${ }^{20}$ Goodyer, M., "Investigation into R J Mitchell test enviroment," AASU Memo 97/01 1-7, 1997.

${ }^{21}$ Dougherty, R. P., Aeroacoustic measurements, chap. Beamforming In Acoustics Testing, Springer Verlag, 2002.

${ }^{22}$ Brooks, T. F. and Humphreys, W., "Effect of directional array size on the measurement of airframe noise components," AIAA paper 1999-1958, 1999. 
${ }^{23}$ Zdravkovich, M., Flaherty, A., Pahle, M., and Skelhorne, I., "Some aerodynamic aspects of coin-like cylinders," Journal of Fluid Mechanics, Vol. 360, No. 1, 1998, pp. 73-84.

${ }^{24}$ Lazos, B., "Surface topology on the wheels of a generic four-wheel landing gear," AIAA Journal, Vol. 40, No. 12, 2002, pp. $2402-2411$. 